\title{
Quantifying the burden of trauma imaging on the CT scan service at a major trauma centre in South Africa
}

\author{
AA Bashir ${ }^{1}$, VY Kong ${ }^{2,3}$, RD Weale ${ }^{4}$, JL Bruce ${ }^{3}$, GL Laing ${ }^{3}$, W Bekker ${ }^{3}$, DL Clarke B $^{2,3}$ \\ ${ }^{1}$ Department of Radiology, University of KwaZulu Natal, Durban, South Africa. \\ ${ }^{2}$ Department of Surgery, University of the Witwatersrand, Johannesburg, South Africa \\ ${ }^{3}$ Department of Surgery, University of KwaZulu Natal, Durban, South Africa \\ ${ }^{4}$ Department of Surgery, North West Deanery, Manchester, United Kingdom
}

Corresponding author: Damian Clarke (damianclar@gmail.com)

\begin{abstract}
Background: Imaging is an integral part of trauma management and the huge burden of trauma in South Africa places substantial pressures on radiology resources. This study aims to provide a holistic overview of the burden of trauma imaging and the cost of trauma to a busy CT scanning facility at a tertiary hospital in South Africa.

Methods: We set out to describe and quantify the impact of blunt poly-trauma on CT scanning services at Grey's Hospital in Pietermaritzburg. We aimed to provide a holistic assessment in terms of use of equipment and staff, cost to the hospital and overall usage of CT scanning.

Results: Over the four-year study period, 1572 patients required a CT scan following blunt torso trauma (mean age: 30 years, $81 \%$ males). Of the 1572 patients, 625 had a chest radiograph (40\%), 383 a cervical spine X-ray (24\%), 347 a pelvic X-ray (22\%), 292 a skull X-ray (18\%), 193 a limb X-ray (12\%), 133 an abdominal radiograph (8\%), and 86 a FAST scan (5\%). The 1572 CT included: 967 head, 568 neck, 65 chest, 241 abdominal, 228 pelvic, 12 upper limb, 38 lower limb and 394 had full body (Pan) CT scan. The mean total cost of the CT scanning for blunt poly-trauma is ZAR 12000 . The total cost of CT scanning for blunt poly-trauma is $0.92 \%$ of the total hospital expenditure. Roughly $7.8 \%$ of the total hours worked by the CT scanner over the time period under review was dedicated to blunt poly-trauma.

Conclusion: Blunt poly-trauma is a preventable disease, which has a major financial impact on the healthcare system in general. This study has documented the tremendous burden it places on an already stretched CT scanning service.
\end{abstract}

S Afr J Surg 2019;57(2)

http://dx.doi.org/10.17159/2078-5151/2019/v57n2a2836

\section{Introduction}

South Africa continues to experience an excessive burden of trauma and the management of this disease consumes healthcare resources on many different levels. ${ }^{1-5}$ Trauma continues to restrict the ability of the healthcare system to manage other pressing health demands as it consumes scarce resources, which could have been allocated elsewhere. Road traffic accidents (RTA) are a major preventable cause of trauma in South Africa and frequently result in blunt polytrauma to the entire torso. ${ }^{1-4}$ This type of trauma is costly to treat, as it requires input from multiple specialties, as well as numerous costly operative procedures and intensive care.

Although the impact of blunt poly-trauma on hospital resources has been well described in the general literature, ${ }^{1-4}$ there are a number of areas where the impact of this excessive burden of trauma has been less well documented. One of these areas is the impact of blunt poly-trauma on radiology services. Radiology is a cross-disciplinary resource, which supports many different services and is critical to the modern management of many different diseases. CT scanning is the cornerstone of the management of blunt poly-trauma. However, CT scan is a finite resource and if trauma patients consume it then access to CT scan for other patients is restricted. In addition, a CT scan is an expensive and complex piece of equipment. Frequent and sustained use of CT scan after hours intails a huge service burden, translating into increased maintenance costs. Fully understanding the cost of trauma to the health service is important if we hope to move to an integrated health service in South Africa. ${ }^{6}$ We have developed a number of costing models which have been used to cost a number of diseases in our environment. ${ }^{7-10}$ In light of 
the above, we set out to use these previously developed models to describe and quantify the impact of blunt poly-trauma on the radiology services at Grey's Hospital, Pietermaritzburg. We aimed to provide a holistic assessment in terms of use of equipment and staff, cost to the hospital and overall usage of CT scanning.

\section{Clinical setting}

The city of Pietermaritzburg is the capital of KwaZulu-Natal (KZN) province and the largest city in the western half of KZN with one million inhabitants. The city is the referral point for Western KZN, which is a predominantly rural area with a population of two million people. The Pietermaritzburg Metropolitan Trauma Service (PMTS) maintains a prospective digital registry, which captures data at our institutions. Ethics approval to maintain the registry has been obtained from the Biomedical Research Ethics Committee (BCA221/13 BREC) of the University of KwaZulu-Natal and from the Research Unit of the Department of Health.

\section{Department of Radiology}

Grey's Hospital is a tertiary referral centre, has five radiology consultants, four medical officers and nine registrars with one full-time specialist radiologist on call after hours. It possesses one MDCT (multidetector computed tomography) scanner (Siemens, somatom sensation model), one MRI (Magnetic Resonance Imaging) scanner, one Angiography suite, one screening unit, one mammography suite, one ultrasound department with five ultrasound machines, and one cardiac catheterisation lab.

\section{Methods}

This project used three methodologies to attempt to quantify the impact that trauma has on a busy CT scanning service.

1. Volume of blunt poly-trauma requiring $\mathrm{CT}$ scanning: The trauma database was interrogated for the period from December 2012 to April 2017 to identify all patients who required a CT scan following blunt poly-trauma. The collected data included demographic details, admission vital signs, auditing all association injury by region, categorisation of abdominal and pelvic organ injuries and Injury Severity Score. Data about operative intervention, complications during admission and the final outcome were also audited. All radiological imaging used in this cohort of patients was reviewed and quantified.

1. Financial cost: Costs for individual CT scan investigations were sourced directly from the private radiology services in Pietermaritzburg. The total financial cost of CT scanning was then worked out using these prices.

1. Opportunity cost: This refers to the benefit, profit, or value of something that must be given up, to achieve a different objective. Every resource has a number of different potential uses and choosing to use a resource for a particular objective means that other options and potential uses must be forgone. Although it is difficult to quantify the value of an opportunity cost, a number of proxy markers can be used. We attempted to provide a holistic overview of the opportunity costs of performing CT scans for blunt poly-trauma by looking at a number of metrics.

- We reviewed the staff required to perform each investigation.

- We calculated the contribution of CT scanning for blunt poly-trauma to the total workload of the CT scan department and the total expense of running the hospital. The total number of CT scans over a single month were audited and the number and percentage undertaken for blunt trauma was determined to provide a numerator and denominator.

- The time for each CT scan was worked out based on the following components of performing a CT scan: preparation, scanning, processing and reporting. The total time expended on imaging patients with blunt poly-trauma was calculated.

\section{Statistical analysis}

Means and standard deviations are reported for normally distributed data; and median and inter-quartile range for data not normally distributed. All data analyses were performed using SPSS 24.0 for Mac (SPSS, Chicago, IL)

\section{Results}

Over the four-year period under review, 1572 patients required a CT scan following blunt torso poly-trauma. The mean age was 30 years. There were $1284(82 \%)$ males. The median admission Glasgow Coma Scale (GCS) for the patients was 15 , the median ISS (injury severity score) was 13 (Table 1).

\begin{tabular}{|c|c|c|}
\hline & & $\begin{array}{c}\text { Total cohort } \\
(\mathrm{N}=1572)\end{array}$ \\
\hline $\operatorname{Sex}(n, \%)$ & Male & $(1284,82 \%)$ \\
\hline \multirow[t]{2}{*}{ Age (median) } & & 30 years \\
\hline & Urban & $(71 \%)$ \\
\hline \multirow[t]{2}{*}{ Urban vs Rural (n, \%) } & Rural & $(16 \%)$ \\
\hline & Unknown & $(13 \%)$ \\
\hline Temp oC (median) & & 37 \\
\hline Admission GCS (median, SD) & & $(15,3.7)$ \\
\hline ISS (median, SD) & & $(13,11.3)$ \\
\hline RTS (median, SD) & & $(7.8,0.98)$ \\
\hline
\end{tabular}




\section{Imaging}

Out of 1572 patients, 625 had a Chest X- ray (CXR) (40\%), 383 a cervical spine X-ray (24\%), 347 a pelvic X-ray (22\%), 292 a skull X-ray (18\%). 193 a limb X-ray (12\%), 133 an abdominal X-ray (8\%), 86 a FAST scan (5\%). The 1572 CT included: 967 head 568 neck, 241 abdominal, 228 pelvic, 65 chest, 38 lower limb, 12 upper limb, and 394 had a full body CT scan (pan CT) (Table 2).

\begin{tabular}{lcc} 
Table 2: Imaging modalities & & \\
\hline Type of imaging modality & SUM & Percentage \% \\
\hline CXR & 625 & $38 \%$ \\
AXR & 133 & $8 \%$ \\
Skull XR & 292 & $18 \%$ \\
Neck XR & 383 & $24 \%$ \\
Limb XR & 193 & $12 \%$ \\
FAST Scan & 86 & $5 \%$ \\
XR Pelvis & 347 & $22 \%$ \\
CT Head & 967 & $62 \%$ \\
CT Neck & 568 & $36 \%$ \\
CT Chest & 65 & $4 \%$ \\
CT Abdomen & 241 & $15 \%$ \\
CT Pelvis & 228 & $15 \%$ \\
Pan CT Scan & 394 & $25 \%$ \\
CT Upper Limb & 12 & $0.8 \%$ \\
CT Lower Limb & 38 & $2.4 \%$
\end{tabular}

\section{Abdominal organ injury}

Of the 1572 patients, $78(5.0 \%)$ had a liver injury, $53(3.4 \%)$ had a spleen injury, $52(3.3 \%)$ a kidney injury, $15(1.0 \%)$ a small bowel injury, $6(0.4 \%)$ a diaphragmatic injury, $6(0.4 \%)$ a pancreatic injury, $5(0,3 \%)$ a large bowel injury, $2(0.13 \%)$ a duodenal injury, $1(0.06 \%)$ a stomach injury, and $1(0.06 \%)$ a rectal injury (Table 3 ).

Table 3: Abdominal organ injury

\begin{tabular}{lcc}
\hline \multicolumn{1}{c}{ Abdominal organs } & Sum & Percentage \% \\
\hline Liver & 78 & $5 \%$ \\
Spleen & 53 & $3.3 \%$ \\
Kidney & 52 & $3 \%$ \\
Small bowel & 15 & $1 \%$ \\
Pancreas & 6 & $0.4 \%$ \\
Diaphragm & 6 & $0.4 \%$ \\
Duodenum & 5 & $0.3 \%$ \\
Stomach & 2 & $0.1 \%$ \\
Large bowel & 1 & $0.6 \%$ \\
Rectum & 1 & $0.1 \%$
\end{tabular}

\section{Management and outcomes}

A total of $37(2.4 \%)$ of the patients required a laparotomy and $188(12.0 \%)$ had other surgeries performed. Of the 188 cases, 62 cases required neurosurgery, 41 debridement, 39 tracheostomy, 14 maxillofacial surgery, and 32 other surgery. A total of $179(11.4 \%)$ required intensive care unit (ICU) admission. Of 1572 patients, 74 (4.7\%) died (Table 4).

\begin{tabular}{llcc} 
Table 4: Management and outcome & & \\
\hline & & SUM & $\begin{array}{c}\text { Percentage } \\
\%\end{array}$ \\
\hline Laparotomies & & 37 & $2 \%$ \\
Other surgeries & & 188 & $12 \%$ \\
& Neurosurgery & 62 & $33 \%$ \\
& Debridement & 41 & $22 \%$ \\
ICU & Tracheostomy & 39 & $21 \%$ \\
admission & Maxillofacial & 14 & $7.4 \%$ \\
\multirow{2}{*}{ Outcome } & Other surgery & 32 & $17 \%$ \\
& ICU admission & 179 & $11 \%$ \\
& Died & 74 & $5 \%$ \\
& Survived & 1498 & $95 \%$
\end{tabular}

\section{Cost analysis}

\section{Direct cost}

Using the number of individual scans and the cost of each scan as obtained directly from the private radiology service, a total direct cost of CT scan usage for blunt poly-trauma for the period of study is ZAR 15590000 (Table 5).

\section{Opportunity cost}

Over the time period under consideration, (24\%) of all CT scans were performed for blunt poly-trauma. The total average time needed for: a non-enhanced head CT scan is +/23 minutes, a non-enhanced CT scan neck $+/-38$ minutes, a. pre- and post-contrast neck CT scan $+/-43$ minutes, a preand post-contrast chest $\mathrm{CT}$ scan $+/-46$ minutes, a pre- and post-contrast abdomen CT scan $+/-49$ minutes, a pre-contrast pelvic CT scan $+/-35$ minutes, a pre-contrast upper limb CT scan +/- 33 minutes, an upper limb CT angiogram +/- 41 minutes, a non-enhanced lower limb CT scan $+/-35$ minutes, a lower limb CT angiogram +/- 40,2 minutes and a pan CT scan $+/-61$ minutes. Based on these individual values, the total time devoted to CT scanning blunt poly-trauma patients over the time period under consideration was $+/-1545$ hours or 64 days. This is summarised in Tables 6 and 7 .

The CT scanner machine at Grey's Hospital runs for an average of 12 hours per day or 4380 hours per year. This works out to be 19710 hours (821 days) during the study period. This means that $7.8 \%$ of the total hours worked by the CT scanner over the time period under review were used to scan blunt poly-trauma patients. 
Table 5: The total cost for blunt trauma patients during the study period

\begin{tabular}{lccc}
\hline Type of CT scan for blunt trauma patients & $\begin{array}{c}\text { Number of CT scan done } \\
\text { during four and a half } \\
\text { years }\end{array}$ & $\begin{array}{c}\text { Total price for each kind of } \\
\text { CT scan }\end{array}$ & $\begin{array}{c}\text { Total cost for the period of } \\
\text { study }\end{array}$ \\
\hline Non-enhanced head CT scan & 950 & $\mathrm{R} 3600$ & $\mathrm{R} 3420000$ \\
Enhanced head CT scan & 17 & $\mathrm{R} 5500$ & $\mathrm{R} 93500$ \\
Non-enhanced CT scan neck & 503 & $\mathrm{R} 4500$ & $\mathrm{R} 2263500$ \\
Pre-and post-contrast Neck CT & 65 & $\mathrm{R} 6500$ & $\mathrm{R} 422500$ \\
Pre-and post-contrast chest CT scan & 65 & $\mathrm{R} 6800$ & $\mathrm{R} 442000$ \\
Pre-and post-contrast abdomen CT scan & 241 & $\mathrm{R} 10750$ & $\mathrm{R} 2590750$ \\
Pre-contrast pelvic CT scan & 228 & $\mathrm{R} 4500$ & $\mathrm{R} 1026000$ \\
Pre-contrast upper limb CT scan & 2 & $\mathrm{R} 4250$ & $\mathrm{R} 8500$ \\
Upper limb CT angiogram & 10 & $\mathrm{R} 11000$ & $\mathrm{R} 110000$ \\
Non-enhanced lower limb CT scan & 1 & $\mathrm{R} 4250$ & $\mathrm{R} 4250$ \\
Lower limb CT angiogram & 37 & $\mathrm{R} 13000$ & $\mathrm{R} 481000$ \\
Pan CT scan & 394 & $\mathrm{R} 12000$ & $\mathrm{R} 4728000$ \\
The total cost & & & $\mathrm{R} 15590000=$ \\
\hline
\end{tabular}

*Rates according to the currency exchange on 1 March 2018.

Table 6: The average time calculated for blunt trauma CT scans

\begin{tabular}{|c|c|c|c|c|c|}
\hline & $\begin{array}{c}\text { Average time of } \\
\text { preparation the } \\
\text { patients (minutes) }\end{array}$ & $\begin{array}{l}\text { Average time of } \\
\text { actual scanning } \\
\quad \text { (minutes) }\end{array}$ & $\begin{array}{c}\text { Average time of } \\
\text { processing the } \\
\text { imaging (minutes) }\end{array}$ & $\begin{array}{l}\text { Average time for } \\
\text { reporting (minutes) }\end{array}$ & Total time \\
\hline $\begin{array}{l}\text { Non-enhanced head } \\
\text { CT scan }\end{array}$ & $+/-5 \mathrm{~min}$ & $+/-3 \mathrm{~min}$ & $+/-5 \mathrm{~min}$ & $+/-10 \min$ & $+/-23 \mathrm{~min}$ \\
\hline $\begin{array}{l}\text { Non-enhanced CT } \\
\text { scan neck }\end{array}$ & $+/-5 \min$ & $+/-4 \min$ & $+/-6 \min$ & $+/-23 \min$ & $+/-38 \mathrm{~min}$ \\
\hline $\begin{array}{l}\text { Pre-and post- } \\
\text { contrast Neck CT } \\
\text { scan }\end{array}$ & $+/-7$ min & $+/-6$ min & $+/-6 \mathrm{~min}$ & $+/-24 \min$ & $+/-43 \mathrm{~min}$ \\
\hline $\begin{array}{l}\text { Pre-and post- } \\
\text { contrast chest CT } \\
\text { scan }\end{array}$ & $+/-7 \mathrm{~min}$ & $+/-5 \mathrm{~min}$ & $+/-7 \mathrm{~min}$ & $+/-27$ min & $+/-46 \mathrm{~min}$ \\
\hline $\begin{array}{l}\text { Pre-and post- } \\
\text { contrast abdomen } \\
\text { CT scan }\end{array}$ & $+/-7 \min$ & $+/-7 \mathrm{~min}$ & $+/-7$ min & $+/-27.4 \min$ & $+/-49 \min$ \\
\hline $\begin{array}{l}\text { Pre-contrast pelvic } \\
\text { CT scan }\end{array}$ & $+/-5 \min$ & $+/-2 \min$ & $+/-5 \mathrm{~min}$ & $+/-23 \mathrm{~min}$ & $+/-35 \mathrm{~min}$ \\
\hline $\begin{array}{l}\text { Pre-contrast upper } \\
\text { limb CT scan }\end{array}$ & $+/-5 \min$ & $+/-2 \min$ & $+/-6 \min$ & $+/-19 \min$ & $+/-33 \mathrm{~min}$ \\
\hline $\begin{array}{l}\text { Upper } \operatorname{limb} C T \\
\text { angio }\end{array}$ & $+/-10 \min$ & $+/-3 \mathrm{~min}$ & $+/-9 \min$ & $+/-20 \mathrm{~min}$ & $+/-41 \mathrm{~min}$ \\
\hline $\begin{array}{l}\text { Non-enhanced lower } \\
\text { limb CT scan }\end{array}$ & $+/-7 \min$ & $+/-3 \min$ & $+/-7 \mathrm{~min}$ & $+/-19$ min & $+/-35 \mathrm{~min}$ \\
\hline $\begin{array}{l}\text { Lower limb CT } \\
\text { angio }\end{array}$ & $+/-10 \min$ & $+/-3 \min$ & $+/-8 \min$ & $+/-20 \mathrm{~min}$ & $+/-40 \mathrm{~min}$ \\
\hline Pan CT scan & $+/-11 \mathrm{~min}$ & $+/-8 \mathrm{~min}$ & $+/-10 \mathrm{~min}$ & $+/-32 \mathrm{~min}$ & $+/-61 \mathrm{~min}$ \\
\hline
\end{tabular}




\begin{tabular}{|c|c|c|c|c|}
\hline Type of CT scan & $\begin{array}{l}\text { The average time } \\
\text { needed for the scan }\end{array}$ & $\begin{array}{c}\text { Number of CT } \\
\text { scans }\end{array}$ & $\begin{array}{l}\text { Total time in } \\
\text { minutes }\end{array}$ & Total time in hours \\
\hline Non-enhanced head CT scan & $+/-23 \min$ & 967 & $22434 \mathrm{~min}$ & $+/-374 \mathrm{hrs}$ \\
\hline Non-enhanced CT scan neck & $+/-38 \min$ & 503 & $18913 \mathrm{~min}$ & $+/-315 \mathrm{hrs}$ \\
\hline Pre-and post-contrast Neck CT scan & $+/-43 \min$ & 65 & $2795 \mathrm{~min}$ & $+/-47 \mathrm{hrs}$ \\
\hline Pre-and post-contrast chest $\mathrm{CT}$ scan & $+/-46 \min$ & 65 & $2964 \min$ & $+/-49 \mathrm{hrs}$ \\
\hline Pre-and post-contrast abdomen CT scan & $+/-49 \min$ & 241 & $11761 \mathrm{~min}$ & +/- $196 \mathrm{hrs}$ \\
\hline Pre-contrast pelvic CT scan & $+/-35 \mathrm{~min}$ & 228 & $8026 \mathrm{~min}$ & $+/-134 \mathrm{hrs}$ \\
\hline Pre-contrast upper limb CT scan & $+/-33 \mathrm{~min}$ & 2 & $66 \mathrm{~min}$ & $+/-1 \mathrm{hrs}$ \\
\hline Upper limb CT angio & $+/-41 \min$ & 10 & $408 \mathrm{~min}$ & $+/-7 \mathrm{hrs}$ \\
\hline Non-enhanced lower limb CT scan & $+/-35 \mathrm{~min}$ & 1 & $35 \mathrm{~min}$ & $+/-0.6 \mathrm{hrs}$ \\
\hline Lower limb CT angio & $+/-40 \mathrm{~min}$ & 37 & $1487 \mathrm{~min}$ & $+/-25 \mathrm{hrs}$ \\
\hline \multirow[t]{2}{*}{ Pan CT scan } & $+/-61 \mathrm{~min}$ & 394 & $23837 \mathrm{~min}$ & $+/-397 \mathrm{hrs}$ \\
\hline & & & & $\begin{array}{c}+/-1545 \text { hours } \\
\text { Equivalent to } 64 \\
\text { days }\end{array}$ \\
\hline
\end{tabular}

\section{Discussion}

The burden of trauma in South Africa has shown no signs of abating over the last three decades. Levels of interpersonal violence remain stubbornly high and increasing road usage due to urbanisation has resulted in an emerging epidemic of blunt poly-trauma. ${ }^{1-5}$ Road traffic collisions (RTCs) are eminently preventable, yet there appears to be little progress made towards limiting and reducing the rate of RTCs on South African Roads. ${ }^{1-4}$ This preventable burden of disease translates into significant expenses to the health system, patients and to broader society. ${ }^{5,10}$ This study shows how RTCs impact on CT scanning service in a single institution.

A modern healthcare system can be compared to an ecosystem, in which multiple diverse sub-systems are linked and alterations to one component of the system may have profound and dramatic repercussions on remote components. Costing the impact of diseases on components of a health system is challenging and a variety of costing models have been developed both internationally and locally. ${ }^{7-10}$ Considering, the opportunity costs of imaging blunt poly-trauma is an example. The excessive burden of blunt poly-trauma on radiology services impacts on the other new emerging epidemics in South Africa, namely noncommunicable diseases and diseases of lifestyle..$^{4-6}$ Many of these patients also need access to CT scan and lack of access translates into delays in diagnosis and management. Our current study focuses on the cost of blunt poly-trauma torso trauma to an individual service, namely CT scan, and is comprehensive as it attempts to establish the direct financial costs as well as the opportunity costs incurred. The concept of an opportunity cost reflects the fact that resources are consumed once they are allocated to a particular patient. A consumed resource cannot be used by any other patient. CT scanning for blunt poly-trauma consumes just under one per cent of the total hospital budget. In addition, $7.8 \%$ of the total working time of the CT scanner is devoted to scanning blunt poly-trauma patients.

This study has a number of limitations. The difficulty in establishing costs in the state sector is well known. This forces researchers to use private practice costs and these are not directly comparable. Although private practice costing in South Africa cannot be extrapolated directly to the public service, there are attempts to standardize the cost models across both sectors and the cost of consumable is the same across both sectors. In addition, the proposed roll out of the National Health Insurance will require meaningful comparison of costs between the two sectors..$^{5,11}$

\section{Conclusion}

Blunt poly-trauma is a preventable disease, which has a major financial impact on the healthcare system in general. This study has documented the tremendous burden it places on an already stretched radiology service and highlights the opportunity costs incurred as a result of blunt poly-trauma. Injury prevention programmes to reduce the incidence of RTCs would have saving benefits in terms of both financial and opportunity costs.

\section{Authors contributions and contact details}

Asma Bashir Primary author, data analysis

Ross Weale Manuscript editing and drafting

Victor Kong Analysis and drafting

John Bruce Database maintenance and data retrieval

Grant Laing Design of data capture instrument

Wanda Bekker Drafting, reference checking

Damian Clarke Senior author, general supervision, coordination and assistance at all levels 


\section{Ethical approval:}

We have ethics approval to keep and use this database (BE $197 / 17,221 / 13$ )

\section{Competing interests}

The authors declare that they have no financial or personal relationship(s) which may have inappropriately influenced them in writing this article.

\section{Funding sources}

No funds needed.

\section{Acknowledgments}

We would like to thank Dr Deneys Reitz the head of Radiology Department, Grey Hospital, Pietermaritzburg, KZN, South Africa for his support.

\section{REFERENCES}

1. Hardcastle TC, Oosthuizen G, Clarke D, Lutge E. Trauma, a preventable burden of disease in South Africa: review of the evidence, with a focus on KwaZulu-Natal South African Health Review. Jan 2016;1:179-89.

2. Lutge E, Moodley N, Tefera A, Sartorius B, Hardcastle T, Clarke D. A hospital based surveillance system to assess the burden of trauma in KwaZulu-Natal Province South Africa. Injury. 2016 47(1):135-40.

3. Parkinson F, Kent S, Aldous C, Oosthuizen G, Clarke D. Road traffic crashes in South Africa: the burden of injury to a regional trauma centre. SAMJ. 2013;103(11):850-2.

4. Yerramilli P. South Africa's quadruple burden of disease; in Uncategorized. Posted 3 March 2015. Available at: http://blogs. plos.org/globalhealth/2015/03/southafrica_quadrupleburden/.

5. https://www.timeslive.co.za/news/south-africa/2017-07-05gunshot-wounds-cost-public-hospitals-billions-each-year/ [accessed Dec 2018].

6. Department of Health. National Health Insurance for South Africa-Towards Universal Health Coverage (White Paper). Pretoria: National Department of Health.

7. Schreyögg J. A micro-costing approach to estimating hospital costs for appendectomy in a cross-European context. Health Econ. Jan 2008;17:S59-69.

8. Baji P, Boncz I, Jenei G, Gulácsi L. The short story of copayments for health care services in Hungary - lessons for neighbouring countries'. 'Zdrowie Publiczne i ZarządzanieZeszyty Naukowe Ochrony Zdrowia. 2010;8:37-47.

9. Kong, V., Aldous, C., Handley, J. and Clarke, D. (2013). The cost effectiveness of early management of acute appendicitis underlies the importance of curative surgical services to a primary healthcare programme. The Annals of The Royal College of Surgeons of England, 95(4), pp.280-284.

10. Parkinson, F., Kent, S., Aldous, C., Oosthuizen, G. and Clarke, D. (2014). The hospital cost of road traffic accidents at a South African regional trauma centre: A micro-costing study. Injury, 45(1), pp.342-345.

11. Department of Health (2010). The determination of health prices in the private sector. Pretoria: National Department of Health. 